\title{
The Influence of Environmental Stimuli upon the Human Body in Summer
}

\author{
Yoshihito Kurazumi ${ }^{*}$, Emi Kondo², Kenta Fukagawa ${ }^{3}$ \\ ${ }^{1}$ School of Life Studies, Sugiyama Jogakuen University, Nagoya, Japan \\ ${ }^{2}$ Department of Comprehensive Engineering, Kindai University Technical College, Nabari, Japan \\ ${ }^{3}$ Department of Architecture, Kyushu Sangyo University, Fukuoka, Japan \\ Email: *kurazumi@sugiyama-u.ac.jp
}

How to cite this paper: Kurazumi, Y. Kondo, E. and Fukagawa, K. (2020) The Influence of Environmental Stimuli upon the Human Body in Summer. Health, 12 781-803.

https://doi.org/10.4236/health.2020.127057

Received: June 15, 2020

Accepted: July 13, 2020

Published: July 16, 2020

Copyright (c) 2020 by author(s) and Scientific Research Publishing Inc. This work is licensed under the Creative Commons Attribution International License (CC BY 4.0).

http://creativecommons.org/licenses/by/4.0/

(c) (i) Open Access

\begin{abstract}
Green building practices benefit many users because it imposes less of a burden both on people and the environment and plays a central role in achieving a sustainable lifestyle. Covering rooftops with tall evergreen trees increases evaporation and reduces energy consumption by heating and air conditioning systems. Japan has a cereal-crop culinary culture and rice cultivation is a primary activity. According to the Biophilia Hypothesis exposure to a lush greenery environment conducive to survival facilitates more effective relaxation and recovery from fatigue than simple elimination of stress. The impact of rice paddies is not only about reduction of energy consumption, but also about mitigating the urban environment and its physiological and psychological effects on the human body. Focusing on the spread of the rice canopy and exposure of water surfaces, clarified the reaction of the human body to thermal sensory perception and outdoor thermal environments, and the correlation between them. Rice fields where the rice canopy was smaller, and where ample standing water surfaces received short wavelength solar radiation, have a high heat capacity, which works to increase the longwave length thermal radiation in the time period when the accumulated amount of short wavelength solar radiation increases. Meanwhile, where the spread of the rice canopy was greater, and the surface of the standing irrigation water covered with rice plants, a mitigation effect on the outdoor thermal environment evaluation index of ETFe (enhanced conduction-corrected modified effective temperature) through reduction of long wavelength thermal radiation came into play, and it became clear that thermal sensory perception improved through visual stimuli that engendered images of humidity. The purpose of this study was to clarify the environmental mitigation effect of rice fields in an urban environment. In addition to the physical environmental mitigation effect, it was also shown that rice fields engendered a psychological environ-
\end{abstract}


mental mitigation effect through visual stimuli in the form of natural ground surfaces such as green spaces.

\section{Keywords}

$E T F e$, Outdoor Environment, Paddy Field, Summer, Thermal Comfort, Thermal Sensation

\section{Introduction}

The Intergovernmental Panel on Climate Change (IPCC) states that, in order to meet global scale carbon reduction targets, land, energy, buildings, transportation, and urban areas must be sustainable [1]. Buildings are a particular problem because they are responsible for about $40 \%$ of global $\mathrm{CO}_{2}$ emissions generated due to energy consumption [2]. According to the United States Environmental Protection Agency, energy consumption by heating and air conditioning (HVAC) systems in the U.S. account for $43 \%$ of the total energy consumption in the nation [3].

To achieve a lifestyle characterized by low carbonization, reducing $\mathrm{CO}_{2}$ emitted from buildings is highly significant. The advancement of the green building initiative is a key issue, not only in the construction sector, but also as an environmental strategy around the world. Green buildings reduce the maintenance costs of buildings and bring tremendous economic and environmental advantages. In addition, green buildings benefit the health and productivity of users. Thus, green building imposes less of a burden on people and the environment and plays a central role in achieving a sustainable lifestyle.

Green building saves energy, cuts environmental load, and is gentler on the human body. The green building approach is easily applied to existing buildings in the form of green walls and green roofs. Roof gardens are popular in some parts of the world and perform important ecological functions if they are properly planned and maintained. Besides providing greenery, they retain water for purposes of evaporative cooling. If short evergreens are used for ground cover, plant surfaces can be maintained at about air temperature, helping to reduce building surface temperature overall.

Rooftops covered with tall evergreens increase evaporation, reduce energy consumption, and lower building surface temperatures. For example, in Ginza, one of the nation's leading high-end areas, Hakutsuru Sake Brewing Co., Ltd. has built rooftop rice paddies known as Hakutsuru Ginza Sky Farmstead [4].

According to Nishida et al. [5], because leaf surface area is small, irrigation water temperature in the early stages of rice growth is highly impacted by short wavelength solar radiation. As the rice matures, the short wavelength solar radiation shield factor increases as the surface area of the leaves increases. During the sprouting season, the short wavelength solar radiation shield factor increases further due to the leaf the angle of inclination towards the sun, and irrigation 
water temperature is impacted by air temperature.

Kurazumi et al. [6] are currently implementing an outdoor experiment involving human subjects to clarify the impact of thermal environmental factors on the human body. Standing water in irrigated rice fields are subjected to short wavelength solar radiation. When short wavelength solar radiation stored, long wavelength thermal radiation increases, which enhances the perceived feeling of heat, while thermal sensory perception declines. Comparing urban environments with greenery to urban environments without it, differences occur in the perception of thermal environments. The former is potentially more comfortable and therefore is an important environmental mitigation factor.

Research pertaining to the effects of outdoor summer thermal environments on the water surface of a park pond [7] and ponds used for farming purposes [8] [9] were assessed. Though results differed depending on water depth, water surface temperatures, and wind direction, areas just above the water surface and adjacent to ponds exhibited lower air temperatures than surrounding areas.

However, the effect described above on the air temperature is extremely limited. Where the water surface temperature is higher than the air temperature, the air temperature on the leeward side of the pond blowing over its surface tended to be higher. The microclimate around the water surface area was considered, yet at the same time, it is rare to find research on how this effect impacts the human body.

Other studies on the greening of the ground surface and its impact on the human body clarify the effects of thermal sensory perception by sophisticated cerebral processing brought on by visual stimulation due to natural scenery such as trees and water surfaces. Kurazumi et al. [10] showed that the tolerance limit of the human body was higher for outdoor thermal environment stimuli than for indoor thermal environment stimuli during the summer.

Visual stimuli brought on by natural scenery composed of plants resulted in the thermal sensation of a neutral temperature approximately $3.5^{\circ} \mathrm{C}$ lower than the visual stimulation induced by artificial scenery composed of buildings and paved roads. These results point to a mitigation of heat sensations with natural greenery. This work also clarifies the fact that spaces composed of natural elements such as trees were more effective in improving thermal comfort than those made of inorganic synthetic materials such as concrete and metal, typical of urban scenes.

Kurazumi et al. [11] conducted quantitative studies of visual stimuli of plants, the effect of thermal stimuli on the human body, and the interaction between them. The indoor ETF [12] was shown to improve thermal sensory perception by visual stimuli composed of natural elements in outdoor spaces including greenery such as grass. Even in hot spaces requiring individuals to "endure" the heat, cerebrally-processed thermal sensory perception improved with greenery. This demonstrates the significance of proactively adding visual stimuli in the form of greenery to indoor spaces. 
According to the Biophilia Hypothesis, exposure to an environment conducive to survival is more effective for relaxation and recovery from fatigue than simple elimination of stress [13] [14] [15]. Ulrich [16] asserts that certain natural environmental factors have a healing effect on the human body. When an individual is exposed to an environment conducive to survival, there is an additional physiological function beyond stress reduction that produces better effects and facilitates recovery.

For example, a group of surgery patients in rooms with a view of trees recovered faster than those who had no such view [17]. In addition, where the green covering factors such as small potted plants acted as visual stimuli in office spaces, both thermal sensation and thermal comfort increased from $0.75 \%$ to $4.67 \%$.

Kurazumi et al. [18] showed that when visual stimuli lie with a line-of-sight distance of $4.5 \mathrm{~m}$, the line-of-sight distance is considered the same as the perceived distance, referencing the correlation between line-of-sight distance ETF (conduction-corrected modified effective temperature) and thermal comfort [12]. With a green covering factor of $5 \%$ or less, any feeling of discomfort was improved.

Based on this concept, the impact of rice paddies with tall plants is not only about the reduction of energy consumption, but also about mitigation of the urban environment and its physiological and psychological effects on the human body. In this connection, Kurazumi et al. [6] focused on the spread of the rice canopy and the exposure of water surfaces to clarify the reaction of the human body to thermal sensory perception in outdoor thermal environments and their correlation. The goal was to evaluate the environmental mitigation effect of rice fields on the psychology and well-being of people living in urban environments.

An additional goal was to collect quantitative data on the impact on the human body of outdoor thermal environments. If we can clarify the impact of visual stimuli on thermal sensory perception by humans, it will lessen the burden on people and the environment and facilitate a sustainable lifestyle.

\section{Experimental Plan}

\subsection{Thermal Environment Evaluation Index, ETFe}

The ETFe (enhanced conduction-corrected modified effective temperature) in outdoor spaces was developed by Kurazumi et al. [19]. Tests are underway to investigate the physiological and psychological impact of ETFe on the human body, which has served to clarify the efficacy [20] of the outdoor ETFe.

Outdoor sensational and physiological body temperatures were used to convert individual climate factors into temperature. These factors were: wind speed, long wavelength thermal radiation in outdoor spaces, short wavelength solar radiation, surface temperature on materials exposed to parts of the human body, and relative humidity. These factors were converted into temperature and added to air temperature, enabling standardized on-axis quantification of individual climate elements and the collective impact of outdoor spaces on the human body 
(i.e., the $E T F e$ ) indicate comfort in outdoor environments [21].

$$
\begin{gathered}
E T F e=T_{a}+T V F_{h t a} / h_{f L}+E R F_{h t a L} / h_{f L}+E C F_{h t a} / h_{f L} \\
+E H F_{E T F e} / h_{f L}+E R F_{h t a S} / h_{f L} \\
T V F_{\text {hta }}=\left(h_{o} f c l F c l o f_{c o n v}-h_{c} f c l F c l f_{\text {conv }}\right)\left(T_{s}-T_{a}\right) \\
E R F_{\text {htaL }}=h_{r L} f c l F c l f_{\text {rad }}\left(T_{r L}-T_{a}\right) \\
E C F_{h t a}=h_{d} F c l d f_{\text {cond }}\left(T_{f}-T_{a}\right) \\
E H F_{E T F e}=L w h_{c} f c l F p c l\left(p_{a}-0.5 p_{E T F e}^{*}\right) \\
E R F_{\text {htas }}=R_{S} \\
h_{f L}=h_{o} f_{c l} F_{c l o} f_{c o n v}+h_{r L} f c l F c l f_{\text {rad }}+h_{d} F c l d f_{c o n d}
\end{gathered}
$$

where

ETFe: enhanced conduction-corrected modified effective temperature [K];

$T_{a}$ : air temperature $[\mathrm{K}]$;

$T V F_{h t a}$ : convective heat transfer area combined with the thermal velocity field $\left[\mathrm{W} / \mathrm{m}^{2}\right]$;

$E R F_{h t a L}$ : radiant heat transfer area combined with the effective radiation field concerning the long wavelength thermal radiation in outdoor space $\left[\mathrm{W} / \mathrm{m}^{2}\right]$;

$E R F_{\text {htas: }}$ : radiant heat transfer area combined with the effective radiation field concerning the short wavelength solar radiation in outdoor space $\left[\mathrm{W} / \mathrm{m}^{2}\right]$;

$E C F_{h t a}$ : heat transfer area combined with the effective conduction field $\left[\mathrm{W} / \mathrm{m}^{2}\right]$;

$E H F_{E T F E}$ e effective humidity field at enhanced conduction-corrected modified effective temperature $\left[\mathrm{W} / \mathrm{m}^{2}\right]$;

$h_{r L}$ : radiant heat transfer coefficient concerning the long-wave radiation in outdoor space $\left[\mathrm{W} /\left(\mathrm{m}^{2} \mathrm{~K}\right)\right]$;

$f c l$ : effective surface area of clothing [-];

$f_{\text {conv }}$ convective heat transfer area factor $[-]$;

$f_{\text {cond }}$ conductive heat transfer area factor $[-]$;

$f_{r a d}$ radiant heat transfer area factor [-];

Fcl: thermal efficiency factor of clothing in the exposed airflow area [-];

Fcld: thermal efficiency factor of clothing in the heat conduction area [-];

Fclo: thermal efficiency factor of clothing under the standard condition [-];

Fpcl: permeation efficiency factor of clothing [-];

$h_{c}$ : convective heat transfer coefficient $\left[\mathrm{W} /\left(\mathrm{m}^{2} \mathrm{~K}\right)\right]$;

$h_{\dot{d}:}$ resultant heat conductance $\left[\mathrm{W} /\left(\mathrm{m}^{2} \mathrm{~K}\right)\right]$;

$h_{f L}$ : sensible heat transfer coefficient in outdoor space $\left[\mathrm{W} /\left(\mathrm{m}^{2} \mathrm{~K}\right)\right]$;

$h_{o}$ : convective heat transfer coefficient under the standard condition [W/ $\left.\left(\mathrm{m}^{2} \mathrm{~K}\right)\right]$;

$L$ : Lewis relation coefficient $[\mathrm{K} / \mathrm{kPa}]$;

$p_{a}:$ water vapor pressure at the outdoor air temperature $[\mathrm{kPa}]$;

$p_{E T F e}^{*}:$ saturated water vapor pressure at enhanced conduction-corrected modified effective temperature $[\mathrm{kPa}]$; 
$R_{S}$ : short wavelength solar radiation heat gain of human body $\left[\mathrm{W} / \mathrm{m}^{2}\right]$;

$T_{s}$ : convection-corrected mean skin temperature [K];

$T_{\dot{f}}$ surface temperature of the contacted material [K];

$T_{r L}$ : mean radiant temperature concerning long wavelength thermal radiation in outdoor space $[\mathrm{K}]$;

w. skin wettedness $[-]$.

\subsection{Experimental Procedure}

The same experimental methodology described in Kurazumi et al. [6] was used to collect and assess data on a quantitative basis. These experiments were conducted during the first half of August 2019 in Fukuoka, Japan, corresponding to the maturation of the rice fields. At the same time, experiments with human subjects were conducted twice a day, before and after 12 noon. The experiment began when the subjects started walking and ended just past the 2-hour mark.

The thermal environment of outdoor summer spaces has, in some instances, deteriorated so much that fatalities from heat stroke have been reported. For this reason, it is best to avoid staying outdoors in direct solar radiation at high temperatures or strong winds at low temperatures for long periods of time. Naturally, it can be conjectured that the human body response will differ the longer the exposure time of the subjects, and the experimental period was determined with consideration for the safety of the subjects.

Measurements of the human body response and the hot environment were taken for 10 min after setting up the measuring equipment, the subjects waited in a standing posture, and the time required for the Assmann Psychrometer to measure the relative humidity. The longer the subjects were exposed to the environment, the more their reactions were likely to differ. For safety, exposure time was limited.

After maintaining a seated position for 60 min or less indoors in an HVAC controlled room, subjects were moved to the first observation point by foot. The experiment staff instructed the subjects that the psychological reporting was thermally specific thermal sensation and thermal comfort, and that they should report the average sensation during the exposure time. The subjects' speed of movement was about $0.7 \mathrm{~m} / \mathrm{s}$.

Upon arriving at the various observation points, the testers installed devices to measure the thermal environment. They waited standing up after the measuring stage was finished. Later, as noted above, they were exposed to the thermal environment for a 10-min period as they stood. The subjects were situated around the thermal environment measuring devices located in the center of the group. Because the experiment concerned the environment surrounding the observation stations, subjects were not limited in terms of a gazing point. After exposure to the environment, the subjects reported the average whole-body thermal sensation and the average whole-body thermal comfort for the whole body that they experienced for the time exposed at the observation point. 


\subsection{Overview of Observation Points}

Observation points are shown in Figure 1 and Table 1 provides an overview of these points. The testers worked with barren land including conditions such as surface gravel and earth, asphalt-pavement, areas of natural covering factors such as greenery and water bodies, and sky factors. For example, the green covering factor is defined as the ratio of green surface solid angles to the celestial globe solid angle. The water covering factor is defined as the ratio of water surface solid angles to the celestial globe solid angle. Three rice paddies where the growth and canopy were widespread, plus two asphalt-covered areas were selected, for a total of five observation points.

\subsection{Subjects}

The subjects were a group of 18 young healthy men and women. The average age of the 12 men was $19.4 \pm 0.8$ years, their height was $170.0 \pm 5.1 \mathrm{~cm}$, and their average weight was $66.5 \pm 12.1 \mathrm{~kg}$. Their body-mass index (BMI) was $22.9 \% \pm$ $3.2 \%$, which meant that none of them were considered unremarkable test subjects. The average age of the 6 women was $18.7 \pm 1.7$ years, while their average height was $159.3 \pm 6.3 \mathrm{~cm}$, and their average weight was $54.8 \pm 10.5 \mathrm{~kg}$. Their BMI was $21.4 \pm 2.4$, which meant that none of them were considered unremarkable test subjects. In compliance with the Helsinki Declaration [22], the subjects were given full information on the procedure in advance and they were required to sign an agreement to participate in the experiment. A body surface area equation proven effective by Kurazumi et al. [23] was used to calculate body surface area [24].

Tests using multiple subjects to measure the reaction of the human body in terms of both physiological and mental components are rare. It is also extremely difficult to extrapolate a small sample to a general population statistically. For this reason, this research is considered significant because it presents a novel set of data.

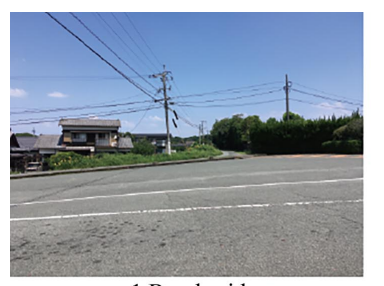

1 Roade side

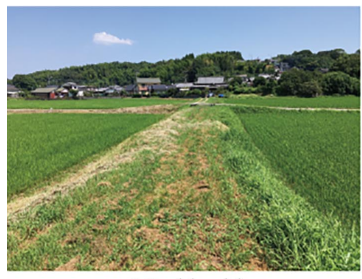

4 Paddy side

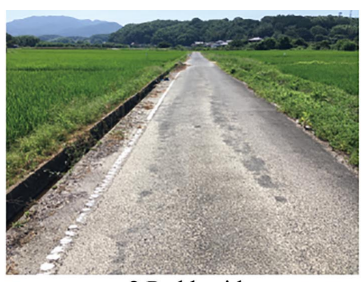

2 Paddy side

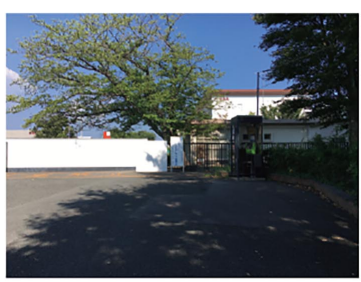

5 Bus stop

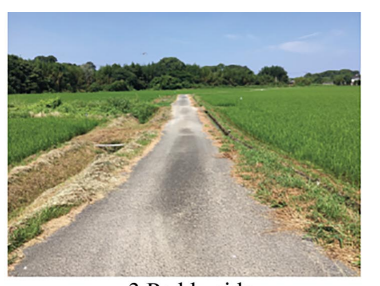

3 Paddy side

Figure 1. Observation points. 
Table 1. Summary of observation points.

\begin{tabular}{ccccccccccc}
\hline Point & Survey point & Ground surface & $\begin{array}{c}\text { Skywards } \\
\text { surface }\end{array}$ & $\begin{array}{c}\text { Surrounds } \\
\text { North side }\end{array}$ & $\begin{array}{c}\text { Surrounds } \\
\text { East side }\end{array}$ & $\begin{array}{c}\text { Surrounds } \\
\text { South side }\end{array}$ & $\begin{array}{c}\text { Surrounds } \\
\text { West side }\end{array}$ & $\begin{array}{c}\text { Sky } \\
\text { factor }\end{array}$ & $\begin{array}{c}\text { Green } \\
\text { factor }\end{array}$ & $\begin{array}{c}\text { Water } \\
\text { factor }\end{array}$ \\
\hline 1 & Roard side & Asphalt & Open & Open & Open & Open & Open & 0.926 & 0.037 & 0.000 \\
2 & Paddy side & $\begin{array}{c}\text { Asphalt \& Paddy } \\
\text { field }\end{array}$ & Open & Open & Open & Open & Open & 0.958 & 0.373 & 0.035 \\
3 & Paddy side & $\begin{array}{c}\text { Asphalt \& Paddy } \\
\text { field } \\
\text { Weed \& Paddy } \\
\text { field }\end{array}$ & Open & Open & Open & Open & Open & 0.969 & 0.357 & 0.002 \\
4 & Paddy side & Open & Open & Open & Open & 0.972 & 0.345 & 0.004 \\
5 & Bus stop & Asphalt \& Weed & Tree & Open & Open & Tree & Open & 0.495 & 0.239 & 0.000 \\
\hline
\end{tabular}

Green factor is green covering factor. Green covering factor is defined as the ratio of green surface solid angles to celestial globe solid angle. Water factor is water covering factor. Water covering factor is defined as the ratio of water surface solid angles to celestial globe solid angle.

\subsection{Experimental Parameters}

Thermal environment conditions are characterized by air temperature, relative humidity, wind speed, short wavelength solar radiation, long wavelength thermal radiation, and ground surface temperature. Air temperature and relative humidity measurements were taken at $90 \mathrm{~cm}$ above ground using the Assmann ventilated psychrometer. Average wind speed was measured for $10 \mathrm{~min}$ at $90 \mathrm{~cm}$ above ground using a hot-surface non-directional wind speed meter (Kanomax Japan Inc.: 6533, measurement range: $0.05-5.00 \mathrm{~m} / \mathrm{s}$ ).

A long and short wavelength radiometer (EKO Instruments: MR-60, sensitivity: $7 \mu \mathrm{V} /\left(\mathrm{Wm}^{-2}\right)$, short wavelength: $305-2800 \mathrm{~nm}$, long wavelength: 5000 $50,000 \mathrm{~nm}$ ) was used to measure radiation levels at a height of $90 \mathrm{~cm}$ above ground, from the visible range to the terrestrial near-mid infrared range short wavelength solar radiation to the terrestrial radiation far-infrared long wavelength thermal radiation. Ground surface temperature was measured with a radiation meter (Konica Minolta: HT-10D, measurement wavelength: $8-14 \mu \mathrm{m}$, measuring angle: $1.4^{\circ}-2.0^{\circ}$, emissivity range: $0.10-1.00$ ).

The photography used to assess the sky factor involved an orthographic projection fisheye lens (Yasuhara: Madoka 180, $7.3 \mathrm{~mm}, \mathrm{f} / 4$ ) and take images of the sky at an observation point from a height of $90 \mathrm{~cm}$ above ground. The percentage of the solid angle of elements in the resultant hemispherical photograph, such as greenery and water surfaces, was calculated by changing the zenith direction and nadir direction (orthographic projection) image to an equi-solid angle (Hugin by Pablo d'Angelo). The albedo, sky temperature, and ground surface temperature were calculated based on the directional components of short wavelength solar radiation and long wavelength thermal radiation.

A thermistor (NIKKISO-THERM: N542R data logger, measurement range: $-50^{\circ} \mathrm{C}-230^{\circ} \mathrm{C}$, resolving power: $0.01^{\circ} \mathrm{C}$ and NIKKISO-THERM: ITP8391 body surface probe) was used to measure skin temperature as a physiological variable in this experiment. Medical-grade moisture-permeable surgical tape (NICHIBAN ${ }^{\mathrm{Tw}}$ : 
NICHIBAN SURGICAL TAPE-21N) was used to affix the surface temperature sensor (for measuring skin temperature) to the subject's body. The temperature of skin exposed to the airflow was measured at seven positions: the head, trunk, arm, hand, thigh, lower leg, and foot. The sole of the foot was measured for the temperature at the point of contact with the skin. Subjects were free to choose their clothing, doing so in accordance with the weather on the date of the experiment. The subjects clothing values were calculated based on combinations of clothing or layers as reported by the subjects [25] [26].

A linear rating scale [27] [28] was used to measure whole-body thermal sensation (i.e., cold or hot) and whole-body thermal comfort (uncomfortable or comfortable) as a psychological precondition of the experiment. The psychological reaction was assessed $10 \mathrm{~min}$ after arrival at the observation point. The entire linear rating scale was converted to numbers using an optional scale of 100 . The linear rating scale indicated only directionality (i.e., hot (100), cold (0), comfortable (100), uncomfortable (0)).

Using thermal sensory perception as an explanatory variable, the following factors rendered significant impacts on physiological and psychological reactions: air temperature, relative humidity, wind speed, short wavelength solar radiation, long wavelength thermal radiation, and temperature of the ground surface where it comes into contact with the human body (sole of foot).

This research takes into consideration the fact that psychological reactions stemming from the outdoor environment tend to be plagued with disturbances, a fact that can produce significant variations. As the standard of comparison between explanatory variables leading to highly effective analysis in a practical sense, the effectiveness rate was observed at 10\%. The software package JMP14.3.0 (SAS Institute Japan) was used for purposes of statistical analysis.

\section{Results}

The number of measurements taken of the subjects at the various observation points totaled 140 . The weather was good on all dates and times that measurements were taken. Table 2 shows the results of the thermal environmental elements measured. There were large discrepancies in short wavelength solar radiation between observation point 5 , in a shady location, and locations $1,2,3$, and 4, which faced the sun. Although dependent on the solar elevation and solar azimuth angle, the downward-facing short wavelength solar radiation was stronger at observation points with high sky factors.

Meanwhile, long wavelength thermal radiation differed greatly between observation points: at stations where direct solar radiation was either blocked or unblocked, the impact of both upward and downward-facing long wavelength thermal radiation was strong. In addition, upward-facing and downward-facing long wavelength thermal radiation at observation point 2 showed only a slight difference when compared to other observation points. Therefore, it is unrealistic to expect significant mitigation due to shading alone. 
Table 2. Results of measurement of thermal environment.

\begin{tabular}{lcccccccccc}
\hline Date & Period & $\begin{array}{c}\text { Survey } \\
\text { point }\end{array}$ & $\begin{array}{c}\mathrm{Ta} \\
{\left[{ }^{\circ} \mathrm{C}\right]}\end{array}$ & $\begin{array}{c}\mathrm{Tf} \\
{\left[{ }^{\circ} \mathrm{C}\right]}\end{array}$ & $\begin{array}{c}\mathrm{RH} \\
{[\%]}\end{array}$ & $\begin{array}{c}\mathrm{Va} \\
{[\mathrm{m} / \mathrm{s}]}\end{array}$ & $\begin{array}{c}\mathrm{RSdwn} \\
{\left[\mathrm{W} / \mathrm{m}^{2}\right]}\end{array}$ & $\begin{array}{c}\text { RSup } \\
{\left[\mathrm{W} / \mathrm{m}^{2}\right]}\end{array}$ & $\begin{array}{c}\text { RLdwn } \\
{\left[\mathrm{W} / \mathrm{m}^{2}\right]}\end{array}$ & $\begin{array}{c}\mathrm{RLup} \\
{\left[\mathrm{W} / \mathrm{m}^{2}\right]}\end{array}$ \\
\hline 3 Aug. 19 & $9: 35-9: 35$ & 1 & 35.7 & 49.9 & 61.9 & 1.05 & 706.0 & 30.6 & 473.8 & 606.4 \\
3 Aug. 19 & $10: 08-10: 18$ & 2 & 34.8 & 51.8 & 60.1 & 1.29 & 780.0 & 42.1 & 493.4 & 622.6 \\
3 Aug. 19 & $10: 32-10: 42$ & 3 & 33.9 & 57.6 & 64.7 & 1.99 & 104.5 & 125.2 & 520.7 & 622.1 \\
3 Aug. 19 & $10: 51-11: 01$ & 4 & 33.7 & 56.9 & 59.2 & 2.46 & 848.7 & 149.3 & 503.1 & 595.2 \\
3 Aug. 19 & $11: 24-11: 34$ & 5 & 34.5 & 34.8 & 59.1 & 2.07 & 62.5 & 0.4 & 488.5 & 527.5 \\
3 Aug. 19 & $13: 56-14: 06$ & 4 & 36.5 & 57.3 & 68.8 & 1.72 & 831.4 & 163.5 & 493.5 & 588.8 \\
3 Aug. 19 & $14: 15-14: 25$ & 3 & 36.1 & 55.7 & 61.9 & 2.42 & 770.6 & 136.0 & 517.8 & 618.0 \\
3 Aug. 19 & $14: 38: 14: 48$ & 2 & 35.3 & 58.7 & 60.4 & 1.70 & 744.2 & 140.5 & 531.1 & 684.0 \\
3 Aug. 19 & $15: 10-15: 15$ & 5 & 34.5 & 36.2 & 63.0 & 1.15 & 40.8 & 0.0 & 504.9 & 534.5 \\
3 Aug. 19 & $9: 59-10: 09$ & 1 & 36.2 & 64.1 & 57.8 & 2.21 & 586.8 & 77.4 & 481.9 & 658.1 \\
4 Aug. 19 & $10: 15-10: 25$ & 4 & 32.9 & 55.2 & 68.5 & 1.36 & 775.9 & 160.5 & 494.3 & 602.6 \\
4 Aug. 19 & $10: 36-10: 46$ & 3 & 31.8 & 54.7 & 71.9 & 2.39 & 817.6 & 158.1 & 509.2 & 624.0 \\
4 Aug. 19 & $11: 07-11: 17$ & 2 & 32.3 & 52.6 & 70.2 & 1.46 & 858.2 & 161.5 & 504.4 & 645.9 \\
4 Aug. 19 & $11: 22-11: 32$ & 5 & 31.4 & 34.2 & 72.9 & 1.24 & 47.2 & 0.1 & 488.1 & 528.1 \\
4 Aug. 19 & $11: 05-11: 15$ & 1 & 33.0 & 60.1 & 68.8 & 1.00 & 912.8 & 28.7 & 486.5 & 663.7 \\
\hline
\end{tabular}

Ta is range of air temperature. Tf is range of ground surface temperature in the vicinity of the human body. RH is range of relative humidty. Va is range of air verocity. RSdwn is range of downward short wave solar radiation. RSup is range of upward short wave solar radiation. RLdwn is range of downward long wave radiation. RLup is range of upward long wave radiation.

Kurazumi et al. [6] [29] [30] [31] showed that thermal sensory perception of the human body due to shadows blocking long wavelength thermal radiation was improved. Nishida et al. [5] and Kurazumi et al. [6], in turn, showed that shallow standing water surfaces demonstrate strong long wavelength thermal radiation, reflect stronger long wavelength thermal radiation from the ground surface, and result in less improvement in the human body's thermal sensory perception.

The results of this research will likely prove consistent with previous studies. Therefore, reducing the impact of long wavelength thermal radiation on rice paddies is considered critical to the mitigation of the outdoor thermal environment. In other words, natural coverings, such as rice fields and water surfaces, are expected to reduce the impact of long wavelength thermal radiation.

Ground surface temperatures of $60^{\circ} \mathrm{C}$ or more were recorded at observation points with asphalt surfaces. Air temperature results also indicate the impact of solar radiation absorptivity on these surfaces due to downward-facing short wavelength solar radiation. In addition, where the ground is covered in plants and where there are water surfaces, the relative impact of ground surface short wavelength solar radiation was relatively low, even when considering factors such as downward-facing short wavelength solar radiation and high air temperatures.

The work of Kurazumi et al. [20] [32] clarified the impact of heat conduction as a variable in outdoor environments that impacts human thermal sensory perception. On ground surfaces where albedo is low, short wavelength solar radiation is strong, and reflected solar radiation is weak, the contact area between the 
standing subject and the ground is minimal. The human body's ability to acquire heat through conduction is projected to heavily impact skin temperature at the contact area (soles of feet).

The average relative humidity was $65.0 \%$, with a standard deviation of $5.0 \%$, a result that does not indicate significant differences in the observed results. As a result, the influence that the difference in evaporation heat exchange has on sensational and physiological temperature is considered to be weak. However, the fact that the observation points are located in high-humidity thermal environments, the environments are thought to yield additional heat and humidity.

The average wind speed was $1.7 \mathrm{~m} / \mathrm{s}$, and all observations were $3.0 \mathrm{~m} / \mathrm{s}$ or less. The standard deviation, which stood at $0.5 \mathrm{~m} / \mathrm{s}$, makes wind speed an environmental factor that potentially affects thermal sensory perception.

Oliveira and Andrade [33] claim that wind speed has the biggest impact on thermal comfort. Kurazumi et al. [20] [32] named air flow as a variable that affects human thermal sensation and thermal comfort in outdoor environments, in both summer and winter.

The human body may incur a negative experience depending on how environmental factors change, and this change may trigger relatively positive experiences. For this reason, other environmental factors, such as those that reduce the thermal effect, may produce a negative reaction.

The ETFe is an index based on the human body's heat balance. To calculate the mean skin temperature used to calculate the heat balance of the human body, a weighting factor was applied in consideration of the convective heat transfer area [34]. The weighting factor [35] was used to calculate mean skin temperature as a physiological reaction of the human body. To calculate body surface area, this research used a formula deemed appropriate by Kurazumi et al. [24].

Human convective heat transfer area, radiant heat transfer area, and conductive heat transfer area are factors borrowed from research by Kurazumi et al. [36]. The projected area factor of the human body comes from the work of Miyamoto et al. [37]. Meanwhile, the radiant heat transfer coefficient and convective heat transfer coefficient for the human body was derived from work by Kuwabara et al. [38]. For emissivity of the human body, a factor of 0.98 , derived from reflectance of electromagnetic waves off skin at wavelengths of $3 \mu \mathrm{m}$ or greater [39], was applied.

Short wavelength solar radiation heat transfer is impacted by solar radiation absorptivity. Kurazumi et al. [40] projected the impact of short wavelength solar radiation absorptivity in outdoor spaces on perceived body temperature when sky factors and albedo are also high. According to VDI3787-2 [41], solar radiation absorptivity is approximately 0.7 for clothed skin. However, Watanabe et al. [42] claim that solar radiation absorptivity of the human body wearing black clothing is 0.76 , while for white clothing it is 0.38 . The solar radiation absorptivity of other clothing combinations, as well as daily wear, fall within the range for black and white clothing. The rate used in this research was 0.70 as derived from reflectance of skin of a wavelength of $3 \mu \mathrm{m}$ or fewer electromagnetic waves by 
Hendler et al. [39] and Elam et al. [43].

Measuring skin moisture proved challenging because it was difficult to ascertain the amount of perspiration, so values were applied from the behavioral thermoregulation model of Kurazumi et al. [44]. This model was used to calculate other missing physiological values. Metabolic heat production was calculated using a correction coefficient from Kurazumi et al. [45] and the outdoor $E T F e$ already proposed and verified theoretically from meteorological observations [19] [20], human body skin temperature, and clothing value of the human body.

\section{Discussion}

\subsection{Relationship between ETFe and Thermal Sensation}

Figure 2 indicates the relationship between the ETFe and thermal sensation. General trends tend toward the hot side of thermal sensation due to a high ETFe despite significant discrepancies.

Outdoor spaces are believed to bring about significant discrepancies in the human body's psychological reaction because they allow freedom of action. In outdoor spaces, we observed not only psychological reaction to the effects of heat, but also discrepancies in thermal sensation due to other environmental stimuli.

Outdoor experiments differ from laboratory experiments because there is greater potential for environmental factors such as visual and auditory sensations to arise. These sensations (responses) can appear as discrepancies in the data. In general, environmental stimuli in outdoor environments are inconsistent and are inconsistent and unpredictable.

Outdoor thermal environmental factors such as short wavelength solar radiation and long wavelength thermal radiation, as well as air flow, were inconsistent and therefore excluded as evaluation factors. These evaluation factors have the potential to impact the human body locally despite evenly distributed heat balance throughout the body. Horikoshi et al. [46] demonstrated changes in directionality caused by local thermal reactions included in psychological reactions to the uneven or asymmetric thermal environment. Kurazumi et al. [47] [48] clarified that inconsistent and/or uneven or asymmetrical environmental factors among the many thermal factors that impact the human body and cause variability in its reactions. In other words, because outdoor spaces are subject to environmental stimuli other than temperature, they produce variable reactions with respect to thermal sensory perception in the human body.

In research involving specific physiological and psychological measurements taken from subjects in outdoor environments, experience suggests that a correlation coefficient of about 0.4 yields good results [6] [10] [20] [21] [29] [30] [31] [32] [49] [50]; in other words, where the coefficient of determination is 0.16 or greater. For this reason, the measurements taken in this research were considered appropriate. 


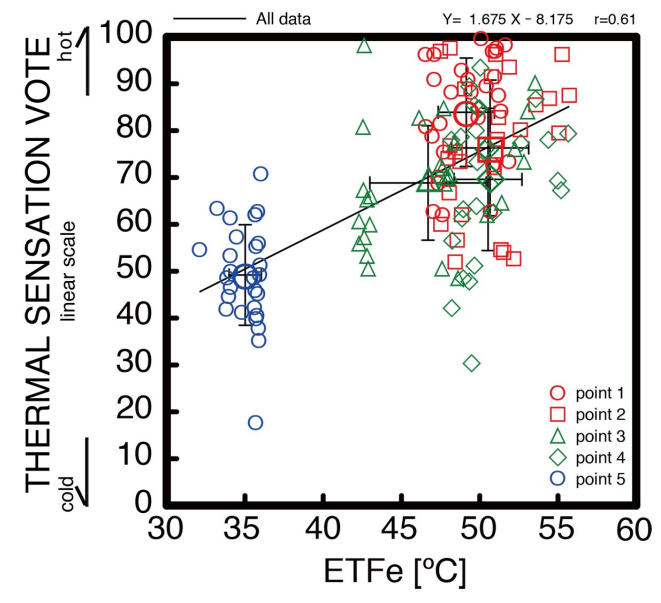

Figure 2. Relationship between ETFe and thermal sensation. Large symbols represent mean \pm SD.

Since trees at observation point 5 obscure the sky, the sky factor was low, which means that short wavelength solar radiation was blocked. Therefore, compared to other observation points, the outdoor ETFe was extremely low. At observation points 1,2,3, and 4, where the sky was not blocked, the impact of short wavelength solar radiation was significantly higher than the outdoor ETFe at point 5 . Thus, point 5 is considered to be a short wavelength solar radiation thermal environment. The relatively low ETFe at observation point 5 was means that the thermal sensation was on the cold side compared to the other points.

The ETFe at observation point 5 stood at an average reading of $35^{\circ} \mathrm{C}$ with a thermal sensation of about 49 . Kurazumi et al. [21] clarified that the outdoor optimum thermal comfort zone ranges from $31.6^{\circ} \mathrm{C}$ to $38.8^{\circ} \mathrm{C}$, and the thermal sensation stands at $35.9^{\circ} \mathrm{C}$ for a neutral rating for thermal sensation of 50 for the summer, which is neither hot nor cold. The retrogressive equation for a neutral rating of 50 for thermal sensation calculated a temperature $34.7^{\circ} \mathrm{C}$. The research results of Kurazumi et al. [21] are consistent with our research results on this point.

The ETFe indices were roughly equal among observation points 1, 2, and 4. At observation point 1 , the thermal sensation measured around 84 , which puts it decisively on the hot side. Meanwhile, points 2 and 4 were ranked 76 and 70, respectively. Regardless of the fact that the ETFe at points 2 and 4 were higher than the ETFs at point 1, the thermal sensation was low (on the cold side), requiring environmental mitigation. The only significant difference between points 2 and 4 was ground cover.

Observation points 2 and 4 were surrounded by rice paddies on the sides of the roads where the subjects stood, and the rice plants were $30-60 \mathrm{~cm}$ tall. The area around observation point 2 felt hotter to the subjects than observation point 4. Kurazumi et al. [6] found that the long wavelength thermal radiation was more prominent during periods in the time period when accumulated amount of short wavelength solar radiation because water surfaces are exposed as the rice 
matures, the water does not flow, and the heat capacity is high.

The impact of this long wavelength thermal radiation means that the area around observation point 2 was hotter than the area around point 4 where the rice paddies were shaded. Although the existence of potential water surfaces of observation point 4 is comprehended, the visual water surface solid angle of observation point 4 is dramatically lower than observation point 2. Kurazumi et al. [17] also clarified thermal sensory perception improved in the case of visual stimulation where the wettability can be easily imagined.

In addition, Kurazumi et al. indicate that for [6] [10] [11] [17] [18], though the physical ETFs are approximately the same, intuitive sensational and physiological body temperature can be shifted by visual stimuli. Therefore, it can be ascertained that the green covering factor had a mitigating effect on thermal sensation in the outdoor environment.

Subjects at observation points 2,3 , and 4 were on roads between rice fields, in which rice stood at a height of $30-60 \mathrm{~cm}$. At point 2 , the rice canopy was relatively small, and a comparison with points 3 and 4 revealed a large water surface area. Nishida et al. [5] claims that the environmental mitigation effect of the paddy field correlates with the depth and flow of the water.

Rice paddies in which the irrigation water is still with low to no flow, have a high heat capacity and the temperature rises. This in turn impacts the accumulation of short wavelength solar radiation and boosts long wavelength thermal radiation. In addition, the quality of thermal radiation is expected to have an impact [47]. For these reasons, the thermal sensation levels at observation point 2 rose compared to points 3 and 4 .

The ANOVA conducted on thermal comfort at each of the locations indicated a significant discrepancy in thermal sensation at each of the observation points (RMSE $=13.19, \mathrm{~F}=26.85, \mathrm{p}<0.01$ ). Focusing on observation points 1,2 , and 4 , which had roughly the same ETFe, and the results of Tukey-Kramer's multiple comparisons, point 1 and point 2 stood at $\mathrm{p}>0.10(\mathrm{p}=0.20)$, which does not indicate a significant differential. However, point 1 and point 4 stood at $\mathrm{p}<0.01$, which is a significant discrepancy. The discrepancy between observation points 2 and 4 was attributed to the water covering factor.

For this reason, we conclude that the impact of the water covering factor is evident in thermal sensation. Kurazumi et al. [17] showed that when visual stimulation evokes an image of wettability, thermal sensory perception improves. In this respect, an image or impression of humidity is more powerful than the visual information of water surface exposure in terms of its environmental mitigation effect.

\subsection{Relationship between the ETFe and Thermal Comfort}

Figure 3 shows the relationship between the ETFe and thermal comfort. Comparing the ERFe and thermal sensation, one observes significant variation. Compared to thermal sensation, thermal comfort is about visual stimulation in 


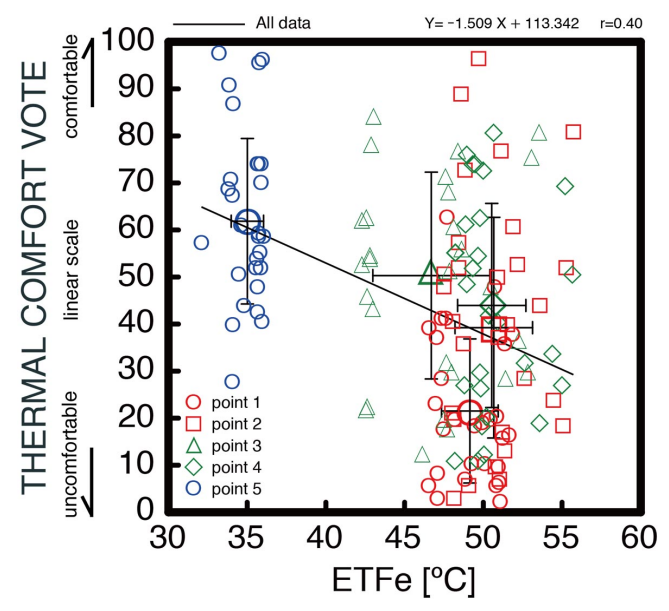

Figure 3. Relationship between ETFe and thermal comfort. Large symbols represent mean \pm SD.

addition to physical thermal stimulation, converting it to thermal sensory perception via highly sophisticated cerebral processing. This yields the possibility of a comprehensive image evaluation.

Another difference between thermal sensation and thermal comfort point to discrepancies in subjects and how they perceived their environment causing significant variations in the data. Regardless of these variations, the overall trends show that when the ETFe is high, thermal comfort is low (on the uncomfortable side).

The relationship between the $E T F e$ and thermal sensation on short wavelength solar radiation due to shading at observation point 5 was low. At points 1 , 2,3 , and 4 , where the impact of short wavelength solar radiation was greater due to an open sky, the ETFe was high, which means they are uncomfortable thermal environments. Because the ETFe was significantly lower at observation point 5, thermal comfort was considered better here than at the other observation points.

Comparing observation points 1, 2, and 4, which had roughly the same ETFe, the discomfort rating at point 1 was 20 , which is exceedingly low. Meanwhile, points 2 and 4 were somewhat comfortable ratings of 40 to 50. Kurazumi et al. [21] found that the optimum thermal comfort zone for outdoor thermal environments ranges from $31.6^{\circ} \mathrm{C}$ to $38.8^{\circ} \mathrm{C}$.

In high temperature areas during the summer season, with 50 being a neutral value, thermal comfort stood at $42.9^{\circ} \mathrm{C}$. Based on a regression equation, the neutral rate of 50 stood at $41.9^{\circ} \mathrm{C}$. The results presented herein are roughly consistent with the research of Kurazumi et al. [21] on this point.

The human body may experience discomfort caused by changes in environmental factors, and these experiences are thought to elicit relative comfort. Therefore, fluctuations that reduce heat are believed to cause comfort. Humphreys [51], Brager and de Dear [52], Nikolopoulou et al. [53], and Kurazumi et al. [21] indicate that expectations of a pleasant environment are low for outdoor spaces. They also showed that thermal sensory perception differs even under 
similar climate conditions. As indicated by Kurazumi et al. [21], expectations on comfort are low for outdoor spaces, which differed from thermal environments reported as comfortable. Because of this factor, the tolerance limit for thermal environment conditions with a high ETFe was accepted.

The major difference between observation points 2 and 4 and observation point 1 was ground cover. At observation points 2 and 4, subjects were situated at roads surrounded by rice paddies where the rice stood at heights of $30-60$ $\mathrm{cm}$. The standing irrigation water in the fields was shaded by the rice, and although the presence of potential water surfaces could be assessed, the solid angle ratio of visual water surfaces was exceedingly low. Kurazumi et al. [17] showed that thermal sensory perception can be improved if visual stimuli elicit an image or impression of wettability. As indicated by Kurazumi et al. [6] [10] [11] [17] [18], the human thermal sensory perception due to visual stimuli can shift, even when the physical outdoor thermal environmental index ETFe remains the

same. Therefore, we propose that the green covering factor contributes to a thermal comfort mitigation effect.

An ANOVA was conducted on thermal comfort at each of the locations, resulting in $\mathrm{p}<0.01$ (RMSE $=20.48, \mathrm{~F}=15.11, \mathrm{p}<0.01$ ), indicating a significant discrepancy in thermal comfort at each of the observation points. Focusing on observation points 1,2 , and 4 , which had roughly the same $E T F e$, the results of Tukey-Kramer's multiple comparisons showed that point 1 and points 2 and 4 stood at $\mathrm{p}<0.05(\mathrm{p}=0.01)$ and $\mathrm{p}<0.01(\mathrm{p}<0.01)$, respectively, indicating a significant differential. The large discrepancy between points 2 and 4 is attributed to the water covering factor. In this respect, an image or impression of wettability is more powerful than the visual information of water surface exposure in terms of environmental mitigation effect.

\subsection{Relationship between Thermal Sensation and Thermal Comfort}

Figure 4 shows the relationship between thermal sensation and thermal comfort. The trend shows that thermal comfort decreases as thermal sensation increases, and discomfort becomes strong. Significant spread in the psychological response of the human body in the outdoor space can be considered to occur due to the degree of freedom of mobility in the experimental environment.

Focusing on the regression line, the thermal comfort at observation point 1 was the highest and the thermal comfort at point 5 was the lowest. An inspection of the parallelism of the regression lines gave $\mathrm{p}>0.10(\mathrm{RMSE}=18.91, \mathrm{~F}=1.00, \mathrm{p}$ $=0.41)$, indicating no significant difference. An inspection of the homogeneity of regression gave $\mathrm{p}<0.01(\mathrm{RMSE}=20.48, \mathrm{~F}=15.11, \mathrm{p}<0.01)$, indicating a significant difference in the homogeneity of the regression lines. As a result of multiple comparisons by Tukey-Kramer, differences between points 1 and 3, points 1 and 4 , points 1 and 5, points 2 and 5, and points 4 and 5 were all significant $\mathrm{p}<$ $0.01(\mathrm{p}<0.01)$; differences between points 1 and 2 was significant $\mathrm{p}<0.05$ ( $\mathrm{p}=$ 


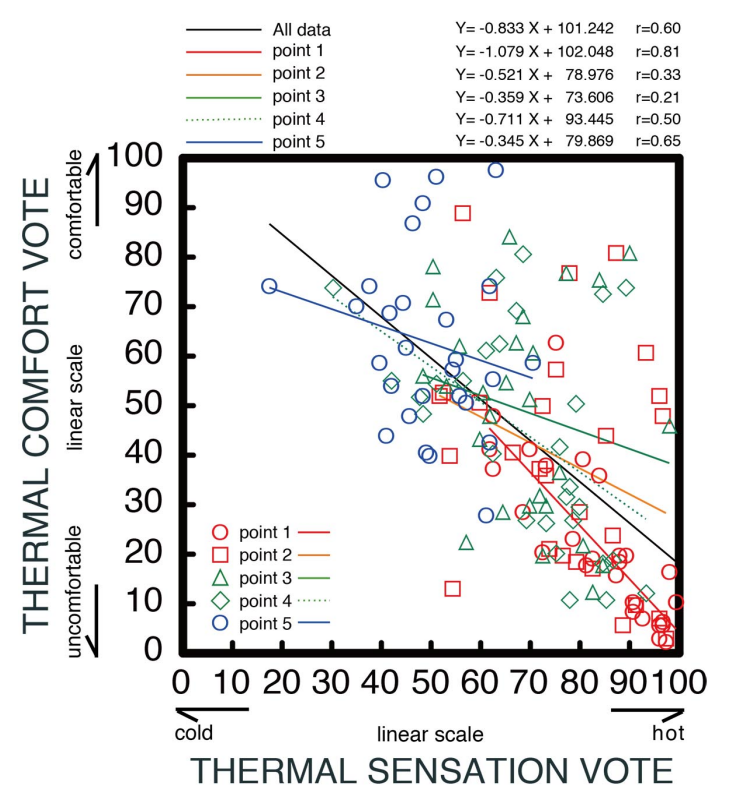

Figure 4. Relationship between thermal sensation and thermal comfort.

0.01 ); therefore, it is clearly shown that improving the physical thermal environment greatly contributes to improving the psychological thermal environment (i.e., thermal sensory perceptions). However, even in such an environment, the natural landscape described in Biophilia [14], the influence of the green and water covering factors find expression in the thermal comfort of human perception.

Focusing on the regression line for all the experimental results, the thermal sensation that produced a thermal comfort level of 50 (neither hot nor cold, but thermally neutral) was 61.5. A comfortable ETFe obtained from the relationship between ETFe and thermal sensation is shown in Figure 2; ETFe was $34.8^{\circ} \mathrm{C}$. As stated in Kurazumi et al. [6] [10] [11], the sense of expectation about the degree of comfort in outdoor spaces is low to begin with and not judged to be comfortable thermal environments, therefore it is conceivable that even thermal environments with a high ETFe were accepted.

Kurazumi et al. [21] showed that an ETFe of $31.6^{\circ} \mathrm{C}-38.5^{\circ} \mathrm{C}$ was perceived to be a comfortable thermal environment range for outdoor spaces in urban areas. As stated in Kurazumi et al. [6], the difference between the perceptual environment (assumed to be comfortable) and the urban environment had an effect in rural and suburban regional environments, resulting in an ETFe below the upper limit of comfort in a summer urban environment [21].

\subsection{Rice Fields and Thermal Sensory Perception}

Figure 5 shows energy converted to temperature from individual meteorological factors and expressed as the ETFe in an example. Values close to the mean at each observation point were selected for analysis. 


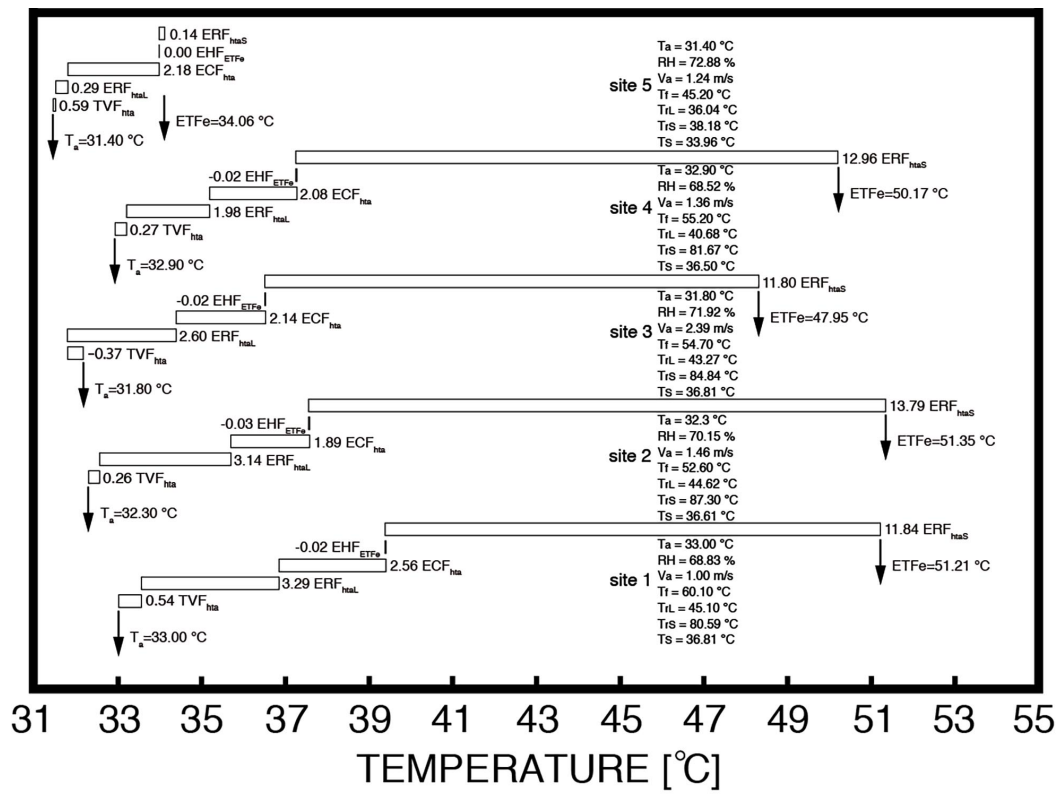

Figure 5. Indication of effect of each thermal environmental factor. ETFe can be expressed as the sum of air temperature and effective temperature deviations caused by $T V F_{\text {hta }}, E R F_{\text {htal }}, E C F_{h t a}, E H F_{E T F e}, E R F_{\text {htas }}$.

Adding the thermal velocity field $T V F_{h t a}$ (indicating impact of wind speed), effective radiation field $E R F_{\text {htaL }}$ (long wavelength thermal radiation), effective radiation field $E R F_{\text {htas }}$ (short wavelength solar radiation), effective conduction field $E C F_{h t a}$ (heat conduction), and effective humidity field $E H F_{E T F e}$ (relative humidity) standard excluded in sensible heat transfer coefficient in outdoor spaces are a good indication of the ETFe [19]. This modification allowed us to quantify both the comprehensive impact and the impacts of individual meteorological factors on sensational and physiological body temperature using the same evaluation axis. Therefore, the adjusting value can be examined by substituting physical and physiological coefficient values such as wind speed, thermal radiant temperature, clothing level, metabolic activity, and area of heat transfer. This means that sensational and physiological body temperature improvements are clarified using temperature-corrected values and the control methodology of target-setting temperatures through environmental factor adjustment are now possible.

The $E R F_{\text {htas }}$ at observation points 1,2,3, and 4 were significantly higher than point 5 because the former locations receive significant sunlight due to open sky, while point 5 is mostly shady. If short wavelength solar radiation could be shut out at point 5, the $E T F e$ would decrease about $10^{\circ} \mathrm{C}$. Because of the regressive equation between $E T F e$ and thermal sensation (Figure 3), and the regressive equation between ETFe and thermal comfort (Figure 4), could possibly mitigate the ETFe to an almost thermally neutral sensation of 50, if the short wavelength solar radiation is blocked at observation points $1,2,3$, and 4 for example.

The $E R F_{\text {htaL }}$ at observation point 2, where rice fields remained, was roughly the same as the $E R F_{\text {htaL }}$ at point 1, it is considered that the influence of the 
ground surface cover is largely manifested. At point 2 , the subjects were in a road between rice fields, the rice canopy was small, and the water covering factor was large. As Kurazumi et al. [6] asserted, the heat capacity of the rice fields as well as the that of standing water, accumulates short wavelength solar radiation, yielding a higher $E R F_{\text {htaL }}$.

As the rice grew and its canopy spread, more of the water surface was shaded, consequently, the $E R F_{\text {htaL }}$ at observation points 3 and 4 was slightly lower. For this reason, physical environmental mitigation of the ETFe can be achieved by reducing the amount of long wavelength thermal radiation.

In addition, in the relationship between ETFe and thermal sensation, and the $E T F e$ and thermal comfort, in cases where visual stimuli evoke an image of wettability, there is an additional effect on sensational and physiological temperature, and it has been shown that thermal sensory perception was improved. Therefore, it became clear that the paddy fields contribute not only to the physical environmental mitigation effect but also to the psychological environmental mitigation effect by visual stimulation as the form of natural ground surfaces such as green spaces.

The Introduction noted that one example of greening a building is a rooftop garden such as the rice field above Hakutsuru Ginza Sky Farmstead [4] in Japan. Covering building rooftops with tall plants reduces building surface temperatures and heating and cooling costs due to shading and evaporative cooling, justifying expectations for a synergistic effect. This research shows that visual stimuli, such as rice fields, impact thermal sensory perception in humans via high-level brain functions.

\section{Conclusions}

Focusing on the environmental mitigation effects, this study, using human subjects, helps to clarify the impact on the human body of thermal environmental factors in outdoor settings. Examining rice canopies and exposed water surfaces in rice paddies, we set out to prove that if we were able to show an impact on thermal sensory perception in humans, induced by visual stimuli (rice fields), it could be used to facilitate a sustainable lifestyle and benefit people and the environment.

Rice fields with smaller canopies and ample standing water receive a greater amount of short wavelength solar radiation, and the heat capacity factor comes into play. Ground cover with high heat capacity has the potential to cause deterioration of thermal sensory perception by intensifying a feeling or perception of heat.

Meanwhile, where the spread of the rice canopy was greater, and the water surfaces where irrigation water remained standing were covered in rice plants, a mitigation effect on the ETFe by reduction of long wavelength thermal radiation came into play, and it became clear that thermal sensory perception improved through visual stimuli that engendered images of wettability. In addition to the 
physical environmental mitigation effect, it was also shown that rice fields engendered a psychological environmental mitigation effect through visual stimuli in the form of natural ground surfaces such as green spaces.

This research shows that the visual stimuli of the rice plants impacts thermal sensory perception in humans.

\section{Acknowledgements}

We would like to express our sincere gratitude to the subjects who participated in this study.

\section{Conflicts of Interest}

The authors declare no conflicts of interest regarding the publication of this paper.

\section{References}

[1] The Intergovernmental Panel on Climate Change (2020) Reports. https://www.ipcc.ch

[2] U.S. Green Building Council (2020) Benefits of Green Building. https://www.usgbc.org/press/benefits-of-green-building

[3] United States Environmental Protection Agency (2020) Indoor Air Quality (IAQ), Health, Energy Efficiency and Climate Change. https://www.epa.gov/indoor-air-quality-iaq/health-energy-efficiency-and-climate-c hange\#energyIAQ

[4] HAKUTSURU SAKE Brewing Co. Ltd. (2020) HAKUTSURU GINZA Sky Farmstead. http://www.hakutsuru.co.jp/g-nouen/about.shtml

[5] Nishida, K., Mitsuyasu, M., Yoshida, S. and Shirozawa, S. (2017) Relationship between Water Depth and Water and Soil Temperature in a Paddy Field during Rice Ripening Period. Irrigation, Drainage and Rural Engineering Journal, 305, I253-I263.

[6] Kurazumi, Y., Kondo, E., Fukagawa, K., Yamato, Y., Tobita, K. and Tsuchikawa, T. (2019) Effects of Outdoor Thermal Environment upon the Human Responses. Engineering, 11, 475-503. https://doi.org/10.4236/eng.2019.118034

[7] Ishii, A., Katayama, T., Nishida, M., Hayashi, T., Shiozuki, Y., Tutsumi, J., Kitayama, H, Takayama, K., Murooka, H. and Ooguro, M. (1989) Thermal Environment in the Urban Area around the Park with a Large Pond, Comparison of When Water Filing and When Water Pumped Out for Cleaning the Bed. Summaries of Technical Papers of Annual Meeting Architectural Institute of Japan, D Environmental Engineering, 1087-1088.

[8] Fukagawa, K., Shimazawa, T., Muranaka, S., Koshikawa, Y. and Ando, M. (2006) A Study of the Differences on the Formation of Temperature among Urban Areas, Rural Areas, and around Irrigation Ponds in a Developing City. Journal of Environmental Engineering (Transactions of AI), 605, 95-102. https://doi.org/10.3130/aije.71.95_2

[9] Fukagawa, K., Murakawa, S., Nishida, D. and Shimazawa, T. (2008) Formation of the Temperature in Summer beside Agricultural Irrigation Ponds Located in Urban Area. Journal of Environmental Engineering (Transactions of AI), 626, 503-510. https://doi.org/10.3130/aije.73.503

[10] Kurazumi, Y., Matsubara, N., Tsuchikawa, T., Kondo, E., Ishii, J., Fukagawa, K., 
Ando, Y., Yamato, Y., Tobita, K. and Horikoshi, T. (2011) Psychological Effects of the Environmental Stimuli on Thermal Sense in Outdoor Spaces. Japanese Journal of Biometeorology, 48, 129-144.

[11] Kurazumi, Y., Fukagawa, K., Kondo, E. and Sakoi, T. (2014) Effects of Visual Stimuli upon Thermal Sense under Air Conditioning in Summer. Journal of Ergonomics, 4, 1-7.

[12] Kurazumi, Y., Tsuchikawa, T., Kondo, E., Horikoshi, T. and Matsubara, N. (2010) Conduction-Corrected Modified Effective Temperature as the Indices of Combined and Separate Effect of Environmental Factors on Sensational Temperature. Energy and Buildings, 42, 441-448. https://doi.org/10.1016/j.enbuild.2009.10.012

[13] Fromm, E. (1964) The Heart of Man: Its Genius for Good and Evil. Harper \& Row Publishers, New York.

[14] Wilson, E.O. (1984) Biophilia. Harvard University Press, Cambridge.

[15] Kellert, S.R. and Wilson, E.O. (1993) The Biophilia Hypothesis. Island Press, Washington DC.

[16] Ulrich, R.S. (1984) View through a Window May Influence Recovery from Surgery. Science, 224, 420-421. https://doi.org/10.1126/science.6143402

[17] Kurazumi, Y., Kondo, E., Fukagawa, K., Hashimoto, R., Nyilas, A., Sakoi, T. and Tsuchikawa, T. (2017) The Influence of Foliage Plants on Psychological and Physiological Responses. Health, 9, 601-621. https://doi.org/10.4236/health.2017.94043

[18] Kurazumi, Y., Hashimoto, R., Nyilas, A., Yamashita, K., Fukagawa, K., Kondo, E., Yamato, Y., Tobita, K. and Tsuchikawa, T. (2018) Effect of Visual Stimuli of Indoor Floor Plants upon the Human Responses. Health, 10, 928-948. https://doi.org/10.4236/health.2018.107069

[19] Kurazumi, Y., Fukagawa, K., Yamato, Y., Tobita, K., Kondo, E., Tsuchikawa, T., Horikoshi, T. and Matsubara, N. (2011) Enhanced Conduction-Corrected Modified Effective Temperature as the Outdoor Thermal Environment Evaluation Index upon the Human Body. Building and Environment, 46, 12-21. https://doi.org/10.1016/j.buildenv.2010.06.012

[20] Kurazumi, Y., Tsuchikawa, T., Matsubara, N., Kondo, E. and Horikoshi, T. (2011) Evaluation of Enhanced Conduction-Corrected Modified Effective Temperature ETFe as the Outdoor Thermal Environment Evaluation Index. Energy and Buildings, 43, 2925-2937. https://doi.org/10.1016/j.enbuild.2011.07.019

[21] Kurazumi, Y., Tsuchikawa, T., Kondo, E., Ishii, J., Fukagawa, K., Yamato, Y., Tobita, K., Ando, Y., Matsubara, N. and Horikoshi, T. (2012) Thermal Comfort Zone in Outdoor Environment. Journal of Human and Living Environment, 19, 115-127.

[22] World Medical Association (2020) WMA Declaration of Helsinki-Ethical Principles for Medical Research Involving Human Subjects. https://www.wma.net/policies-post/wma-declaration-of-helsinki-ethical-principlesfor-medical-research-involving-human-subjects

[23] Kurazumi, Y., Tsuchikawa, T., Kakutani, K., Torii, T., Matsubara, N. and Horikoshi, T. (2003) Evaluation of the Conformability of the Calculation Formula for the Body Surface Area of the Human Body. Japanese Journal of Biometeorology, 39, 101-106.

[24] Kurazumi, Y., Horikoshi, T., Tsuchikawa, T. and Matsubara, N. (1994) The Body Surface Area of Japanese. Japanese Journal of Biometeorology, 31, 5-29.

[25] Hanada, K., Mihira, K. and Ohhata, K. (1981) Studies on the Thermal Resistance of Women's Underwear. Journal of the Japan Research Association for Textile End-Use, 22, 430-437.

[26] Hanada, K., Mihira, K. and Sato, Y. (1983) Studies on the Thermal Resistance of 
Men's Underwear. Journal of the Japan Research Association for Textile End-Use, 24, 363-369.

[27] Horikoshi, T. and Kobayashi, Y. (1985) Corrected Humid Operative Temperature as an Index of Combined Influences of Thermal Conditions upon the Human Body. Journal of Architecture, Planning and Environmental Engineering (Transactions of AI), 355, 12-19. https://doi.org/10.3130/aijax.355.0_12

[28] Horikoshi, T., Kobayashi, Y. and Tsuchikawa, T. (1991) Indices of Combined and Independent Effect of Thermal Environmental Variable upon the Human Body. ASHRAE Transactions, 97, 228-238.

[29] Kurazumi, Y., Ishii, J., Fukagawa, K. and Aruninta, A. (2015) The Influence of Tropical Urban Climate upon the Human Body. International Joint-Conference of SENVAR-iNTA-AVAN2015 (SIA 2015), Johor, 24-26 November 2015, 105-114.

[30] Kurazumi, Y., Ishii, J., Fukagawa, K., Kondo, E. and Aruninta, A. (2016) Ethnic Differences in Thermal Responses between Thai and Japanese Females in Tropical Urban Climate. American Journal of Climate Change, 5, 52-68. https://doi.org/10.4236/ajcc.2016.51007

[31] Kurazumi, Y., Ishii, J., Fukagawa, K., Kondo, E., Nyilas, A. and Aruninta, A. (2017) Seasonal Differences of Psychological and Physiological Responses in Tropical Urban Climate. Health, 9, 896-920. https://doi.org/10.4236/health.2017.96064

[32] Kurazumi, Y., Kondo, E., Ishii, J., Sakoi, T., Fukagawa, K., Bolashikov, Z.D., Tsuchikawa, T., Matsubara, N. and Horikoshi, T. (2013) Effect of the Environmental Stimuli upon the Human Body in Winter Outdoor Thermal Environment. Journal of Environmental and Public Health, 2013, Article ID: 418742. https://doi.org/10.1155/2013/418742

[33] Oliveira, S. and Andrade, H. (2007) An Initial Assessment of the Bioclimatic Comfort in an Outdoor Public Space in Lisbon. International Journal of Biometeorology, 52, 69-84. https://doi.org/10.1007/s00484-007-0100-0

[34] Kurazumi, Y., Tsuchikawa, T., Torii, T., Kakutani, K., Matsubara, N. and Horikoshi, T. (2004) Weighting Coefficients for Calculating Mean Skin Temperature When Considering Convective Heat Transfer Areas. Journal of the Human-Environmental System, 7, 19-28. https://doi.org/10.1618/jhes.7.19

[35] Kurazumi, Y., Matsubara, N., Furukawa, N., Fujiwara, M., Ue, A., Ueki, Y., Nagai, H. and Yamamoto, S. (1998) Japanese Weighting Coefficients for Calculating Mean Skin Temperature in Relation to Posture. Japanese Journal of Biometeorology, 35, 121-132.

[36] Kurazumi, Y., Tsuchikawa, T., Matsubara, N. and Horikoshi, T. (2008) Effect of Posture on the Heat Transfer Areas of the Human Body. Building and Environment, 43, 1555-1565. https://doi.org/10.1016/j.buildenv.2007.09.001

[37] Miyamoto, S., Horikoshi, T. and Hirokawa, Y. (1998) Projected Area Factors of the Human Body at Standing Posture under Different Clothing Conditions. Journal of Architecture, Planning and Environmental Engineering (Transactions of AI), 513, 47-52. https://doi.org/10.3130/aija.63.47_4

[38] Kuwabara, K., Mochida, T., Kondo, M. and Matsunaga, K. (2003) Measurement of Man's Convective Heat Transfer Coefficient by Using a Thermal Manikin in the Middle Wind Velocity Region. Journal of Human and Living Environment, 8, 27-32.

[39] Hendler, E., Crosbie, R. and Hardy, J.D. (1958) Measurement of Heating of the Skin during Exposure to Infrared Radiation. Journal of Applied Physiology, 12, 177-185. https://doi.org/10.1152/jappl.1958.12.2.177 
[40] Kurazumi, Y., Sakoi, T. and Nyilas, A. (2018) The Influence of the Solar Radiation Absorptivity up on the Outdoor Thermal Environment Evaluation Index and the Thermal Sensory Perceptions. American Journal of Climate Change, 7, 204-217. https://doi.org/10.4236/ajcc.2018.72014

[41] VDI (2008) VDI 3787-2, Environmental Meteorology-Methods for the Human Biometeorological Evaluation of Climate and Air Quality for Urban and Regional Planning at Regional Level-Part 1: Climate. Beuth, Berlin.

[42] Watanabe, S., Horikoshi, T. and Tomita, A. (2010) Measurement of Solar Radiation Absorptance of Clothed Human Body in Outdoor. Japanese Journal of Biometeorology, 47, 165-173.

[43] Elam, R., Goodwin, D.W. and Lloyd Williams, K. (1963) Optical Properties of the Human Epidermis. Nature, 198, 1001-1002. https://doi.org/10.1038/1981001a0

[44] Kurazumi, Y., Sakoi, T., Tsuchikawa, T., Fukagawa, K., Bolashikov, Z.D. and Horikoshi, T. (2014) Behavioral Thermoregulation Model for Evaluation of Outdoor Thermal Environment. Journal of Ergonomics, 4, 1-14.

https://doi.org/10.4172/2165-7556.1000125

[45] Kurazumi, Y., Nakamura, R. and Matsubara, N. (2000) Effect of Different Postures on the Resting Metabolic Rate of Young Japanese at Operative Temperature of 28 ${ }^{\circ} \mathrm{C}$. Japanese Journal of Biometeorology, 37, 27-37.

[46] Horikoshi, T., Kurazumi, Y., Hirayama, K., Tsuchikawa, T. and Kobayashi, Y. (1989) Indication of the Effect of Asymmetric Thermal Radiation of the Human Physiological and Psychological Responses. The Second World Congress on Heating, Ventilating, Refrigerating and Air Conditioning-CLIMA 2000 III, Sarajevo, 27 August-1 September 1989, 188-193.

[47] Kurazumi, Y., Horikoshi, T., Hirayama, K., Tsuchikawa, T. and Kobayashi, Y. (1993) The Influence of Asymmetric and Uneven Thermal Radiation Environments upon the Human Body, in the Case of Constant Operative Temperature. Journal of Architecture, Planning and Environmental Engineering (Transactions of A.I.J.), 447, 17-26. https://doi.org/10.3130/aijax.447.0_17

[48] Kurazumi, Y., Saito, K. and Horikoshi, T. (1994) The Influence of Asymmetric Thermal Radiation Environments upon the Human Body, in the Case of Constant Operative Temperature and Right and Left, Back and Forth Asymmetry. Japanese Journal of Biometeorology, 31, 75-84.

[49] Kurazumi, Y., Ishii, J., Kondo, E., Fukagawa, K., Bolashikov, Z.D., Sakoi, T., Tsuchikawa, T., Matsubara, N. and Horikoshi, T. (2014) The Influence of Outdoor Thermal Environment on Young Japanese Female. International Journal of Biometeorology, 58, 963-974. https://doi.org/10.1007/s00484-013-0681-8

[50] Kurazumi, Y., Fukagawa, K., Kondo, E., Yamato, Y. and Tobita, K. (2015) The Influence of Solar Radiation upon the Human Body. The 15th Science Council of Asia Conference and International Symposium (SCA2015), Siem Reap City, 15-16 May 2015, 154-158.

[51] Humphreys, M. (1976) Field Studies of Thermal Comfort Compared and Applied. Building Services Engineer, 44, 5-27.

[52] Brager, G.S. and de Dear, R.J. (1998) Thermal Adaptation in the Build Environment, a Literature Review. Energy and Buildings, 27, 83-96.

https://doi.org/10.1016/S0378-7788(97)00053-4

[53] Nikolopoulou, M., Baker, N. and Steemers, K. (2001) Thermal Comfort in Outdoor Urban Spaces, Understanding the Human Parameter. Solar Energy, 70, 227-235. https://doi.org/10.1016/S0038-092X(00)00093-1 